\title{
Flavonoids and saponins extracted from black bean (Phaseolus vulgaris L.) seed coats modulate lipid metabolism and biliary cholesterol secretion in C57BL/6 mice
}

\author{
Rocio A. Chavez-Santoscoy ${ }^{1}$, Janet A. Gutierrez-Uribe ${ }^{1}$, Omar Granados ${ }^{2}$, Ivan Torre-Villalvazo ${ }^{2}$, \\ Sergio O. Serna-Saldivar ${ }^{1}$, Nimbe Torres ${ }^{2}$, Berenice Palacios-González ${ }^{2}$ and Armando R. Tovar ${ }^{2 *}$ \\ ${ }^{1}$ Centro de Biotecnología FEMSA, Escuela de Biotecnología y Alimentos, Tecnológico de Monterrey, Campus Monterrey, \\ Avenida Eugenio Garza Sada 2501 Sur, C.P. 64849 Monterrey, NL, Mexico \\ ${ }^{2}$ Departamento de Fisiología de la Nutrición, Instituto Nacional de Ciencias Médicas y Nutrición Salvador Zubirán, \\ Vasco de Quiroga No. 15, C.P. 14000 Mexico, DF, Mexico
}

(Submitted 21 August 2013 - Final revision received 19 February 2014 - Accepted 24 February 2014 - First published online 24 July 2014)

\section{Abstract}

Black bean (Phaseolus vulgaris L.) seed coats are a rich source of natural compounds with potential beneficial effects on human health. Beans exert hypolipidaemic activity; however, this effect has not been attributed to any particular component, and the underlying mechanisms of action and protein targets remain unknown. The aim of the present study was to identify and quantify primary saponins and flavonoids extracted from black bean seed coats, and to study their effects on lipid metabolism in primary rat hepatocytes and C57BL/6 mice. The methanol extract of black bean seed coats, characterised by a HPLC system with a UV-visible detector and an evaporative light-scattering detector and HPLC-time-of-flight/MS, contained quercetin 3-O-glucoside and soyasaponin Af as the primary flavonoid and saponin, respectively. The extract significantly reduced the expression of SREBP1C, FAS and HMGCR, and stimulated the expression of the reverse cholesterol transporters $A B C G 5 / A B C G 8$ and $C Y P 7 A 1$ in the liver. In addition, there was an increase in the expression of hepatic PPAR- $\alpha$. Consequently, there was a decrease in hepatic lipid depots and a significant increase in bile acid secretion. Furthermore, the ingestion of this extract modulated the proportion of lipids that was used as a substrate for energy generation. Thus, the results suggest that the extract of black bean seed coats may decrease hepatic lipogenesis and stimulate cholesterol excretion, in part, via bile acid synthesis.

Key words: Black beans: Lipid metabolism: Saponins: Flavonoids

Dysfunctional lipid homeostasis plays an important role in the initiation and progression of atherosclerotic lesions ${ }^{(1)}$. Statins are clinically used to reduce the levels of cholesterol in serum and thus reduce the risk of heart disease ${ }^{(2)}$. However, it has been stated by the National Cholesterol Education Program Expert Panel (ATP III) that dietary strategies must be used before introducing medications for the treatment of hypercholesterolaemia ${ }^{(3,4)}$. A number of dietary modifications have been proposed to reduce the levels of cholesterol in serum, including the consumption of soya protein, PUFA and dietary phytosterols, among other bioactive compounds ${ }^{(5-10)}$. Interestingly, natural phytochemicals can have synergistic effects, and lower doses of each bioactive compound can attenuate hypercholesterolaemia ${ }^{(11-13)}$.
Several studies have suggested that bean consumption has a hypocholesterolaemic effect ${ }^{(14,15)}$. However, in these studies, bean components that exerted the hypocholesterolaemic effect were not identified. Black bean (Phaseolus vulgaris L.) seed coats are a rich source of natural compounds, such as flavonoids and saponins, that have beneficial effects on human health ${ }^{(16)}$. Flavonoids are polyphenols that have long been recognised as having many beneficial activities, such as antioxidant, anti-inflammatory and hepatoprotective activities $^{(17)}$. Saponins are secondary plant metabolites with multiple biological activities being attributed, including hypocholesterolaemic effects ${ }^{(18,19)}$.

It has not been clearly established whether dietary bioactive compounds from black bean could modulate cholesterol

\footnotetext{
Abbreviations: ABCG, ATP-binding cassette, subfamily G; AMPK, AMP-activated protein kinase; CPT1, carnitine palmitoyltransferase 1; CYP7A1, cholesterol $7 \alpha$-hydroxylase; FSE, extract rich in flavonoids and saponins from black bean seed coats; HMGCR, 3-hydroxy-3-methylglutaryl-CoA reductase; INSIG, insulin-induced gene; LXR, liver X receptor; SREBP, sterol regulatory element-binding protein.
} 
Table 1. Diet composition of the six tested experimental diets offered to C57BL/6 mice*

\begin{tabular}{lcccccc}
\hline Ingredients (g/kg) & $\mathrm{CN}$ & $\mathrm{CN}+\mathrm{FSE}(\mathrm{L})$ & Chol & Chol+FSE (H) & Chol+FSE (L) & Chol+Sim \\
\hline Casein & 200 & 200 & 200 & 200 & 200 & 200 \\
Dextrin & 132 & 132 & 127 & 127 & 127 & 127 \\
Soyabean oil & 70 & 70 & 70 & 70 & 70 & 70 \\
Cellulose & 50 & 50 & 50 & 50 & 50 & 50 \\
Choline & $2 \cdot 5$ & 2.5 & 2.5 & 2.5 & 2.5 & 2.5 \\
Saccharose & 100 & 100 & 100 & 100 & 100 & 100 \\
Starch & 397.486 & 397.486 & 397.486 & 397.486 & 397.486 & 397.486 \\
Vitamins & 10 & 10 & 10 & 10 & 10 & 10 \\
Minerals & 35 & 35 & 35 & 35 & 35 & 35 \\
Cystein & 3 & 3 & 3 & 3 & 0.014 & 3 \\
tert-Butylhydroquinone & 0.014 & 0.014 & 0.014 & 0.014 & 5 & 0.014 \\
FSE & 0 & 2.5 & 0 & 5 & 5 & 0 \\
Cholesterol & 0 & 0 & 5 & 0 & 0 & 5 \\
Simvastatin & 0 & 0 & 0 & 0.3 \\
\hline
\end{tabular}

$\mathrm{CN}$, control diet; CN+FSE (L), control diet with the flavonoid- and saponin-rich extract $(0.25 \%)$; Chol, control diet with cholesterol $(0.5 \%)$;

Chol+FSE $(\mathrm{H})$, control diet with cholesterol $(0.5 \%)$ and the extract $(0.5 \%)$; Chol+FSE $(\mathrm{L})$, control diet with cholesterol $(0.5 \%)$ and the extract $(0.25 \%)$; Chol+Sim, control diet with cholesterol $(0.5 \%)$ and simvastatin $(0.03 \%)$.

${ }^{*}$ Diets were made according to the standards of the AIN-93G diet (control).

homeostasis via the transcription factors sterol regulatory element-binding proteins (SREBP) and liver X receptor (LXR). Lipid homeostasis in vertebrate cells is regulated by a family of membrane-bound transcription factors such as SREBP. On the one hand, SREBP directly activate the expression of more than thirty genes involved in the synthesis and uptake of cholesterol and fatty acids ${ }^{(20,21)}$. On the other hand, LXR can modulate the expression of the transporters ATP-binding cassette subfamily $\mathrm{G}$ members ( $A B C G 5 / A B C G 8$ ). These reverse cholesterol transporters are glycoproteins synthesised in the endoplasmic reticulum ${ }^{(22,23)}$. They are expressed in a tissuespecific manner in the liver, colon and intestine ${ }^{(24)}$, and are responsible for limiting intestinal absorption of cholesterol and promoting biliary excretion of sterols ${ }^{(25)}$.

Therefore, the aim of the present study was to identify and quantify the main saponins and flavonoids extracted from black bean seed coats, and to study their effects on the expression of lipogenic genes, specifically those involved in reverse cholesterol transport and $\beta$-oxidation in primary rat hepatocytes. The study also assessed the intestinal and hepatic effects of these compounds on genes involved in the same aforementioned pathways in primary rat hepatocytes and in bile acid synthesis in $\mathrm{C} 57 \mathrm{BL} / 6$ mice.

\section{Experimental methods}

\section{Samples of seed coats}

$P$. vulgaris $\mathrm{L}$. var. San Luis was obtained from Sinaloa, Mexico and stored at $4^{\circ} \mathrm{C}$ and $85 \%$ relative humidity. The beans were soaked in a plastic bag with distilled water at a ratio of 100:1 $(\mathrm{w} / \mathrm{v})$ for $24 \mathrm{~h}$ at room temperature. The conditioned black beans were dried for $6 \mathrm{~h}$ at $60^{\circ} \mathrm{C}$. Later, seed coats were removed using a mechanical seed decorticator (SC-DGE 4364; Square D). The decortication time was $90 \mathrm{~s}$. The resulting milled material was separated by three nested sieves into cotyledons $(2.81 \mathrm{~mm})$, seed coats $(1.00 \mathrm{~mm})$, and a mixture of fine cotyledon, hilum and seed coat debris $(0 \cdot 251 \mathrm{~mm})$.

\section{Extraction of flavonoids and saponins from black bean seed coats}

The extraction of flavonoids and saponins was performed at $35^{\circ} \mathrm{C}$ for $3 \mathrm{~h}$ at $250 \mathrm{rpm}$ with $80 \%$ methanol in water $(\mathrm{v} / \mathrm{v})$ using a mass:solvent ratio of $1: 10(\mathrm{w} / \mathrm{v})$. The supernatant was recovered and vacuum filtered through a Whatman filter paper no. 1. The resulting extract was concentrated in a rotary evaporator to remove methanol. The bath temperature was set at $60^{\circ} \mathrm{C}$, and the pressure in the vacuum pump set at a range of -70 to $-90 \mathrm{kPa}$. After the removal of methanol, the concentrated extract was lyophilised, and the resulting freezedried powder was stored at $-80^{\circ} \mathrm{C}$.

\section{Fractionation of the methanol extract}

The fractionation of the extract was performed by solid-phase extraction using a Strata C18 cartridge $(55 \mu \mathrm{m}, 20 \mathrm{~g} / 60 \mathrm{ml}$; Phenomenex). First, the black bean seed coat extract (FSE), rich in flavonoids and saponins, was resuspended in methanol $(0 \cdot 1 \mathrm{~g} / \mathrm{ml})$. The column was conditioned first with methanol and then with distilled water $(-50 \mathrm{kPa})$. Subsequently, the soluble extract was passed through the cartridge, followed by $60 \%$ $(\mathrm{v} / \mathrm{v})$ methanol acidified with $0 \cdot 1 \%(\mathrm{v} / \mathrm{v}) \mathrm{HCl}$ and then by $60 \%$ (v/v) methanol without acidification. This first elution yielded the flavonoid-rich fraction. Lastly, methanol was passed through the cartridge to obtain the saponin-rich fraction. Both fractions were concentrated and lyophilised as described previously.

\section{Quantification and identification of flavonoids and saponins}

The quantification of flavonoids and saponins was performed using a HPLC system with a UV-visible detector and an evaporative light-scattering detector (1200 Series; Agilent Technologies). The HPLC system was equipped with a Zorbax SB-Aq $(3 \times 150 \mathrm{~mm}, 3.5 \mu \mathrm{m})$ column, and data were collected using Agilent ChemStation. Separation conditions used were as reported previously ${ }^{(16)}$. The concentrations of saponins 
Table 2. Sequences of real-time PCR primers* designed for expression studies in Mus musculus

\begin{tabular}{|c|c|c|c|c|}
\hline Genes & & Primer $\left(5^{\prime}-3^{\prime}\right)$ & $T_{\mathrm{m}}\left({ }^{\circ} \mathrm{C}\right)$ & Amplified fragment size (bp) \\
\hline \multirow[t]{2}{*}{$A B C G 5$} & Forward & cagaggagatgcttggcttc & $60 \cdot 01$ & 240 \\
\hline & Reverse & tgaaaggaaccgtgggtaag & 59.96 & \\
\hline \multirow[t]{2}{*}{$A B C G 8$} & Forward & cctctcaggtgccttggttt & $59 \cdot 89$ & 175 \\
\hline & Reverse & acgtcgagtagtgaggctct & 60.04 & \\
\hline \multirow[t]{2}{*}{ AMPK } & Forward & acctgagaacgtcctgcttg & $59 \cdot 97$ & 155 \\
\hline & Reverse & ggcctgcgtacaatcttcct & $60 \cdot 11$ & \\
\hline \multirow[t]{2}{*}{ CYP7A1 } & Forward & tgggctgtgctctgaagttc & $60 \cdot 25$ & 211 \\
\hline & Reverse & ctgtgtccaaatgccttcgc & $60 \cdot 11$ & \\
\hline \multirow[t]{2}{*}{ FAS } & Forward & caaaggaccaagcattgccc & 55.00 & 238 \\
\hline & Reverse & tacaacagcctcagagcgac & $55 \cdot 00$ & \\
\hline \multirow[t]{2}{*}{$F X R$} & Forward & ggcactcccatttacaggct & 60.03 & 260 \\
\hline & Reverse & accagtcttccggttgttgg & $60 \cdot 18$ & \\
\hline \multirow[t]{2}{*}{ HMGCR } & Forward & gggtattgctggectcttca & 59.74 & 215 \\
\hline & Reverse & ggattgccattccacgagct & $60 \cdot 75$ & \\
\hline \multirow{2}{*}{ INSIG1 } & Forward & tagccaccatcttctcctcc & $58 \cdot 21$ & 300 \\
\hline & Reverse & gccaacgaacacggcaatac & $60 \cdot 45$ & \\
\hline \multirow[t]{2}{*}{ INSIG2 } & Forward & ggttttggccttggtgttgg & $60 \cdot 18$ & 153 \\
\hline & Reverse & tcccatcgttatgcctccag & $59 \cdot 24$ & \\
\hline \multirow[t]{2}{*}{$L X R-\alpha$} & Forward & aagatgcaggagaccaggga & $60 \cdot 25$ & 207 \\
\hline & Reverse & gctcgttccccagcattttg & $60 \cdot 11$ & \\
\hline \multirow[t]{2}{*}{$L X R-\beta$} & Forward & ttcgggcttccactacaacg & $60 \cdot 32$ & 326 \\
\hline & Reverse & tgcttgcttccgaagtgc & 58.55 & \\
\hline \multirow[t]{2}{*}{ SREBP1c } & Forward & agacaaactgcccatccacc & $60 \cdot 25$ & 216 \\
\hline & Reverse & aagcggatgtagtcgatggc & $60 \cdot 25$ & \\
\hline \multirow[t]{2}{*}{ SREBP2 } & Forward & atgatcaccccgacgttca & 59.83 & 120 \\
\hline & Reverse & gtcacgaggctttgcacttg & $60 \cdot 04$ & \\
\hline
\end{tabular}

and flavonoids were calculated as soyasaponin I and aglycone equivalents, respectively, using standards (Sigma).

The identities of flavonoids and saponins were confirmed by HPLC-time-of-flight/MS (Model G1969A Agilent 1100; Agilent Technologies) with the same chromatographic conditions as described previously. Mass spectral data were collected using electrospray ionisation in a positive mode under the following conditions: $\mathrm{m} / \mathrm{z}$ range, $100-1400 ; \mathrm{N}_{2}$ gas; gas temperature, $250^{\circ} \mathrm{C}$; flow rate of the dry gas, 13 litres/ min; nebuliser pressure, $344738 \mathrm{~Pa}$; capillary voltage, $4000 \mathrm{~V}$; fragment voltage, $70 \mathrm{~V}$. Extracted ion chromatograms were obtained based on the accurate masses obtained for the compounds or their adducts with $\mathrm{Na}$ or $\mathrm{K}$ with an error range of 0.01 units, using Analyst QS 1.1 software (Applied Biosystems).

\section{Culture of primary rat hepatocytes}

Rat hepatocytes were isolated by collagenase perfusion and separated from non-parenchymal liver cells by centrifugation at $325 \mathbf{g}$, as reported previously ${ }^{(26)}$. Primary hepatocytes were plated in a six-well plate $\left(9.6 \mathrm{~cm}^{2} /\right.$ well) (Corning CellBIND). At $4 \mathrm{~h}$ after plating the hepatocytes, FSE, the flavonoid- or saponin-rich fraction and/or T0901317, a high-affinity LXR agonist $(10 \mu \mathrm{M})$, was added. The concentrations used were based on the most abundant compounds, such as quercetin 3-Oglucoside $(100 \mu \mathrm{M})$ and soyasaponin Af $(1 \mu \mathrm{M})$. The hepatocytes were stimulated for $24 \mathrm{~h}$ for each treatment. Each treatment was performed in triplicate.

\section{Animals and dietary groups}

Male $\mathrm{C} 57 \mathrm{BL} / 6$ mice were bred and raised at the animal facility of the Instituto Nacional de Ciencias Médicas y Nutrición Salvador Zubiran in Mexico City. A total of forty-eight mice (21 d old, initial weight $12-15 \mathrm{~g}$ ) were randomly assigned to six experimental groups; the size of the sample was determined by the well-known method called power analysis. Each group was fed ad libitum for $35 \mathrm{~d}$ with one of the experimental diets detailed in Table 1 . The diets were carefully prepared according to the standards of the AIN-93 diet for laboratory rodents ${ }^{(27)}$. All animals were maintained under standard environmental conditions $\left(20^{\circ} \mathrm{C}\right.$, diurnal cycle $12 \mathrm{~h}$ light $-12 \mathrm{~h}$ dark).

Food consumption and body weight were recorded every 3-5 d. The effects of the diets on energy metabolism were determined during the 4 th week (detailed in the next section). During the last week, faeces were collected daily. At the end of the study, mice were killed in a $\mathrm{CO}_{2}$ chamber after $12 \mathrm{~h}$ of food deprivation. Blood was collected via the portal vein, and serum was obtained by centrifugation at $1000 \boldsymbol{g}$ for $10 \mathrm{~min}$ and stored at $-80^{\circ} \mathrm{C}$ until further analysis. The liver and ileum were rapidly excised, frozen in liquid $\mathrm{N}_{2}$ and stored at $-80^{\circ} \mathrm{C}$. The animal protocol was approved by the Institutional Animal Care and Research Advisory Committee of the Instituto Nacional de Ciencias Médicas y Nutrición in México City. 
(A)

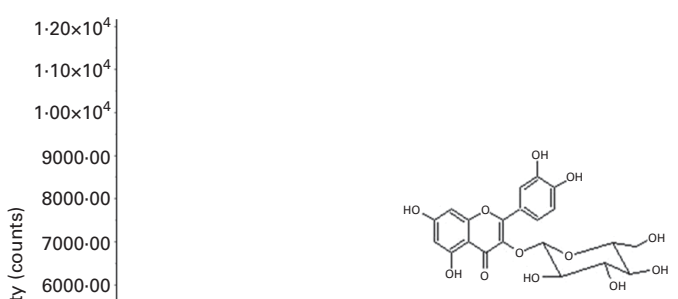

(C)

B)
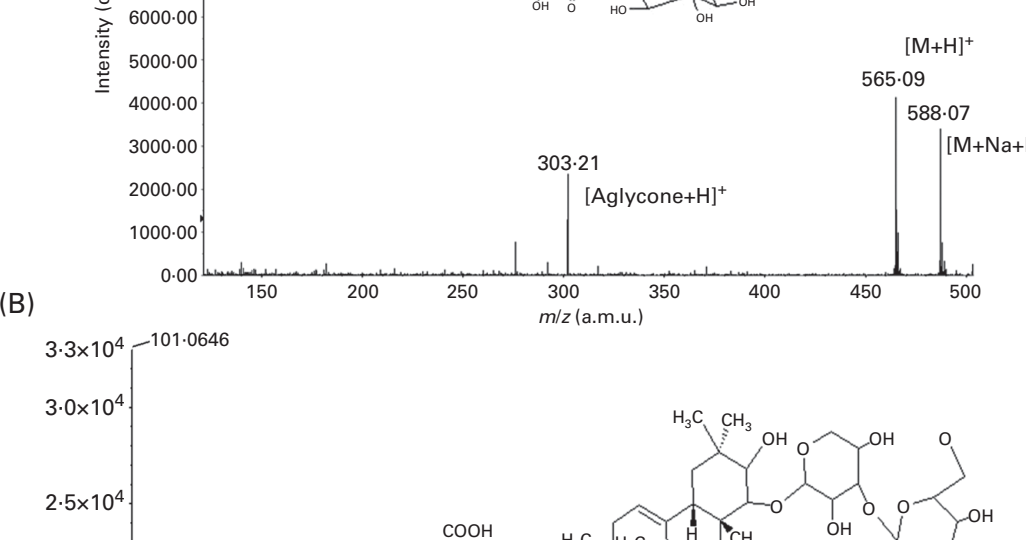

$m / z$ (a.m.u.)

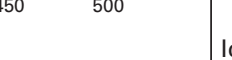

Identified saponins

Phaseoside I

Soyasaponin Af

Deacetyl soyasaponin Af

Soyasaponin $\mathrm{Ba}$

Soyasaponin $\alpha g$

Soyasaponin $\beta \mathrm{g}$

Soyasaponin $\gamma g$

Identification and concentration of compounds from the black bean seed coat extract

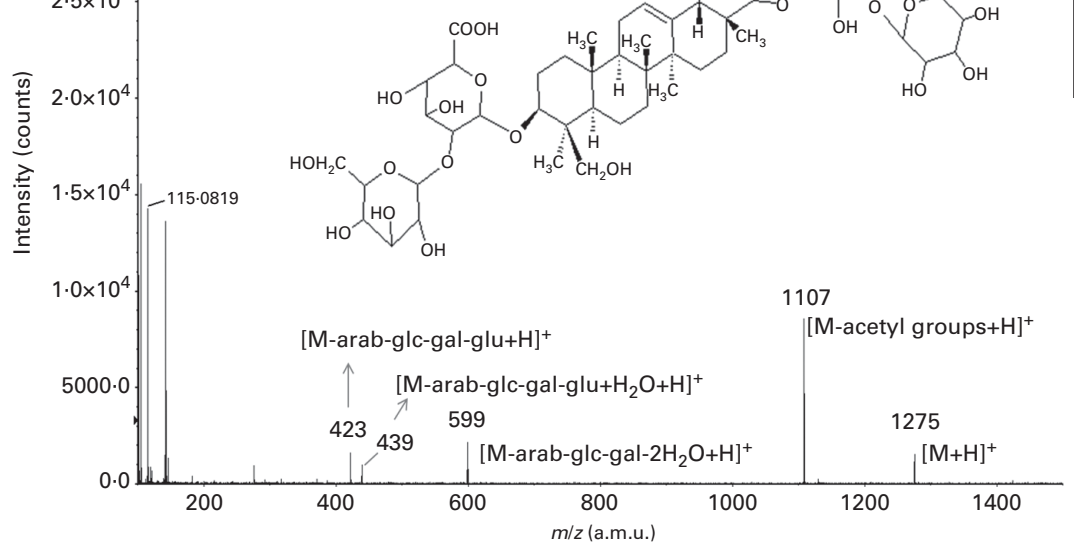

Fig. 1. Extraction and identification of compounds from black bean seed coats. Mass spectra of the major (A) flavonoid (quercetin $3-O$-glucoside) and (B) saponin (soyasaponin Af) extracted from black bean seed coats. (C) Amounts of other compounds identified in the black bean seed coat extract. a.m.u., Atomic mass unit; arab, arabinose; glc, glucoside; gal, galactose; glu, glucose.

\section{Determination of the effects of the diets on energy} metabolism

$\mathrm{O}_{2}$ consumption, $\mathrm{CO}_{2}$ production and food intake were measured using a laboratory animal monitoring system (Columbus Instruments). From each experimental group, three mice were housed individually in Plexiglas cages for $3 \mathrm{~d}$ and three nights, and 0.6 litres of air per min were passed through each cage. Detectors that were previously calibrated with primary gas standards of high purity were used to measure the $\mathrm{O}_{2}$ and $\mathrm{CO}_{2}$ levels sequentially in each chamber for $45 \mathrm{~s}$. The RER was calculated as the average volume of $\mathrm{CO}_{2}$ produced $\left(\mathrm{VCO}_{2}, \mathrm{ml} / \mathrm{kg}\right.$ per $\left.\mathrm{h}\right)$ by the three mice over the $3 \mathrm{~d}$ and three nights divided by the volume of $\mathrm{O}_{2}$ consumed $\left(\mathrm{VO}_{2}, \mathrm{ml} / \mathrm{kg}\right.$ per $\left.\mathrm{h}\right)$.

\section{Quantification of serum biochemical parameters and lipids in the liver}

The levels of total cholesterol, TAG, HDL- and LDL-cholesterol were measured in serum obtained from food-deprived mice using a COBAS C111 analyser (Roche). The concentration of insulin in serum was measured by ELISA according to the manufacturer's protocol (Merck KGaA). Total lipids were extracted twice from homogenised hepatic tissue with chloroformmethanol (2:1) solution. The organic layer was dried under $\mathrm{N}_{2}$, solubilised in isopropanol/Triton X-100 (10\%) and then assayed to determine the concentrations of total cholesterol and TAG using enzymatic kits (DiaSys Diagnostic Systems GmbH).

\section{Histological analysis}

Liver samples were dissected and immediately fixed with icecold 4\% (w/v) paraformaldehyde in PBS and embedded in paraffin. For each block, two $4 \mu \mathrm{m}$ sections were then stained with haematoxylin and eosin. To visualise neutral lipids, frozen liver sections $(8 \mu \mathrm{m})$ were stained with Oil Red O (Sigma). Stained slides were imaged with a Sony CCS-IRIS digital camera coupled to a Leica microscope at $20 \times$ magnification.

\section{RNA extraction and real-time RT-PCR}

Total RNA from the hepatocytes and tissue was obtained using TRIzol reagent, quantified using a NanoDrop spectrophotometer 
(A)
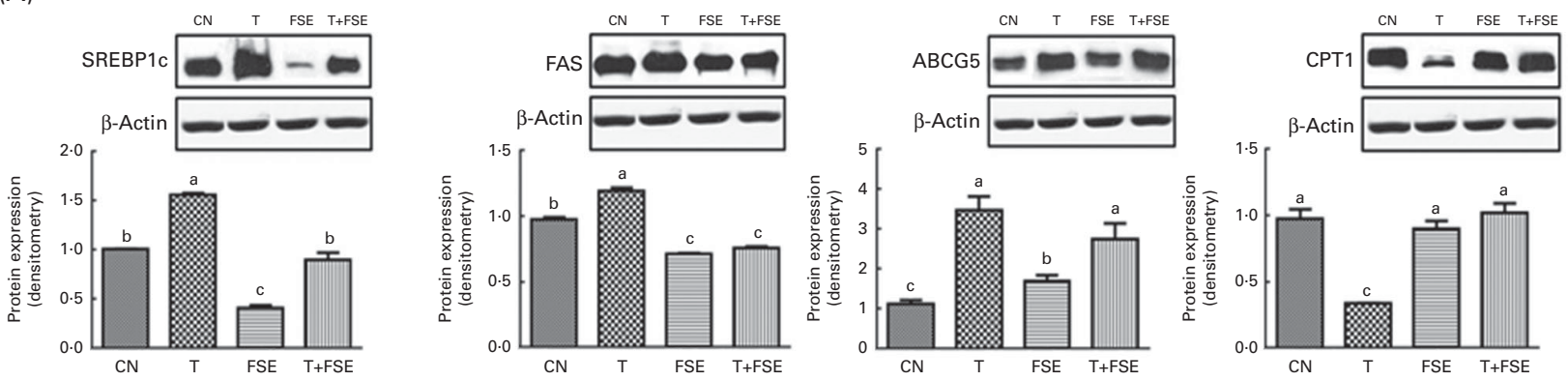

(B)

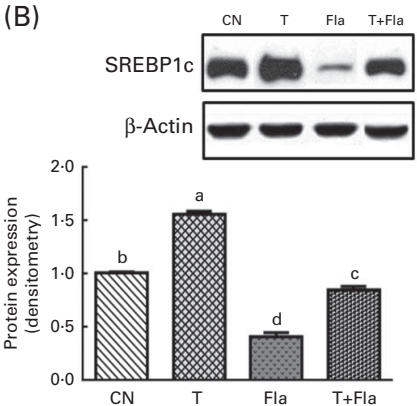

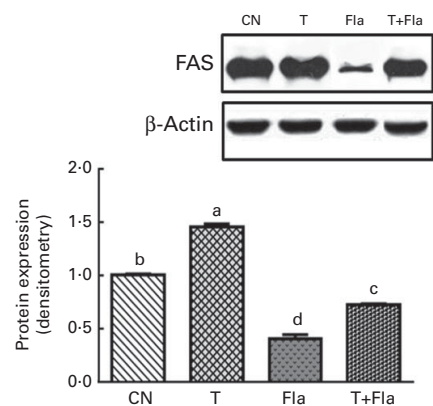

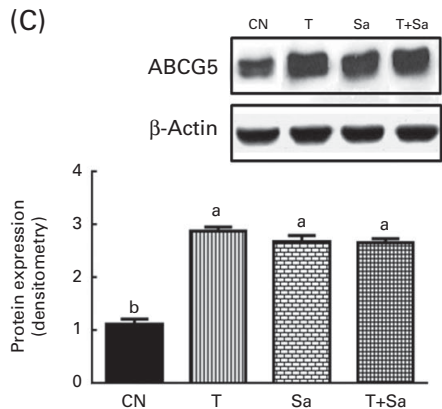

Fig. 2. Effects of the black bean seed coat extract on the expression of key proteins involved in lipid metabolism. (A) Relative expression and protein levels of sterol regulatory element-binding protein 1c (SREBP1c) and fatty acid synthase (FAS) (key lipogenic proteins), ATP-binding cassette, subfamily G5 (ABCG5, a key protein in reverse cholesterol transport) and carnitine palmitoyltransferase 1 (CPT1, a key protein in $\beta$-oxidation) in primary rat hepatocytes treated with no stimulus (control diet; $\mathrm{CN}$ ), the synthetic liver $\mathrm{X}$ receptor (LXR) agonist T0901317 (T; $10 \mu \mathrm{M})$, the flavonoid- and saponin-rich extract (FSE) at a concentration of $100 \mu \mathrm{M}$ based on the major compound (quercetin 3-O-glucoside), or T0901317 and the extract at the same dose (T+FSE). (B) Relative expression and protein levels of SREBP1c and FAS in primary rat hepatocytes treated with no stimulus (CN), the synthetic LXR agonist T0901317 (T; $10 \mu \mathrm{M})$, the flavonoid-rich fraction (Fla) at a dose of $100 \mu \mathrm{m}$ based on the major compound (quercetin 3-O-glucoside), or T0901317 and the flavonoid-rich fraction at the same dose (T+Fla). (C) Relative expression and protein levels of ABCG5 in primary rat hepatocytes treated with no stimulus (CN), the synthetic LXR agonist T0901317 (T; $10 \mu \mathrm{M})$, the saponin-rich fraction (Sa) at a dose of $1 \mu \mathrm{m}$ based on the major compound (soyasaponin Af), or T0901317 and the saponin-rich fraction at the same dose (T+Sa). Values are means, with their standard errors represented by vertical bars. ${ }^{a, b, c, d}$ Mean values with unlike letters were significantly different $(P<0.05)$.

(NanoDrop Technologies), and reverse transcribed. PCR amplification was performed in a Roche LightCycler 480 II using the TaqMan or SYBR Green System. Primers for PCR amplification were designed using the program Primer3 (Howard Hughes Medical Institute) to obtain an amplicon size of $100-350 \mathrm{bp}$ (Table 2). Relative expression levels were calculated by the $2^{-\Delta \Delta C_{\mathrm{T}}}$ method $^{(28)}$. Assays for each gene were performed in triplicate in ninety-six-well optical plates.

\section{Protein extraction and Western blotting}

Protein extraction and Western blotting were performed as reported previously ${ }^{(29)}$. Briefly, for each experimental group, equal quantities of protein from each mouse were pooled for Western blotting analysis of tissues. Total protein (30 or $40 \mu \mathrm{g}$ ) was loaded onto $8 \%$ polyacrylamide gels, separated by SDS-PAGE and transferred to polyvinylidene difluoride membranes. The membranes were blocked with non-fat dry milk (Bio-Rad) and incubated overnight at $4^{\circ} \mathrm{C}$ with the following primary antibodies: anti-SREBP1c; anti-SREBP2 (Millipore); anti-ABCG5 and ABCG8; anti-fatty acid synthase (FAS); anti-carnitine palmitoyltransferase 1 (CPT1); anti-3hydroxy-3-methylglutaryl-CoA reductase (HMGCR); antiinsulin-induced gene 1 and 2 (INSIG1 and INSIG2); anti-total and phosphorylated AMP-activated protein kinase (AMPK and p-AMPK); anti-peroxisome proliferator-activated $\alpha$ receptors (PPAR- $\alpha$ ) (Santa Cruz Biotechnology). Then, the blots were incubated with a secondary antibody and visualised using a ChemiDoc $^{\text {TM }}$ XRS+ System with Image Lab ${ }^{\text {TM }}$ Software (BioRad). Bands were analysed using the ImageJ $1.42 \mathrm{p}$ digital imaging processing program (http://rsb.info.nih.gov/ij/March/27/2012).

\section{Faecal bile acid analysis by GC}

Dried faecal samples from each experimental group (100 mg) were diluted in saline solution, and norcholic acid was added as an internal standard (100 mg/l). Bile acids from the faeces were extracted and quantified as described previously ${ }^{(30)}$

\section{Statistical analysis}

Results are expressed as means with their standard errors. Data were analysed with GraphPad 6.0 (Prism) and MINITAB 16 (Minitab Inc.) software. To identify significant differences among the groups, statistical analysis was performed by oneway ANOVA followed by Tukey's test. The distribution type of the variables was examined using the Kolmogorov-Smirnov $Z$ test. Logarithmic transformation was performed before 

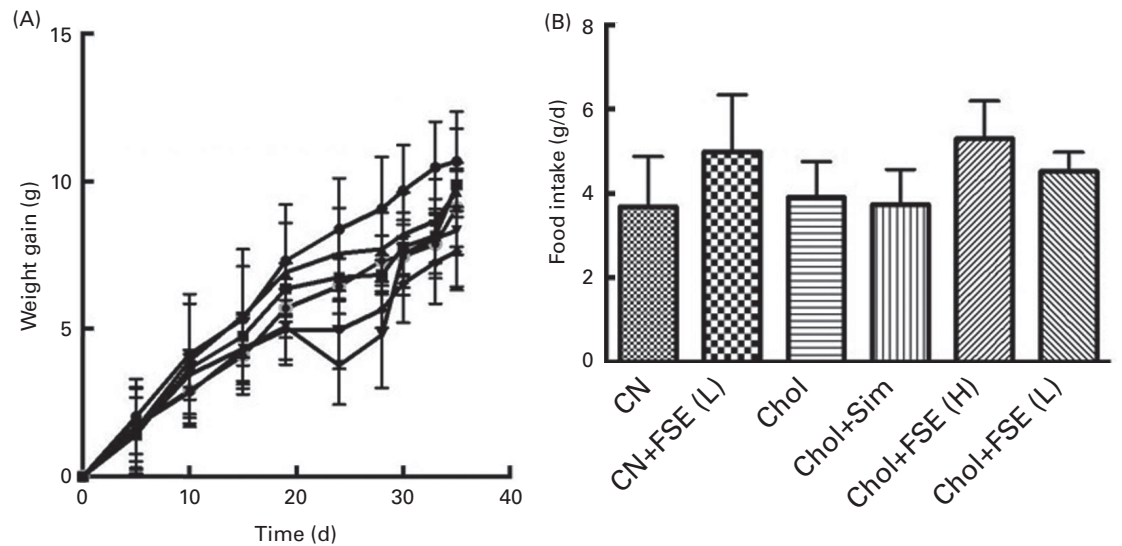

(C)

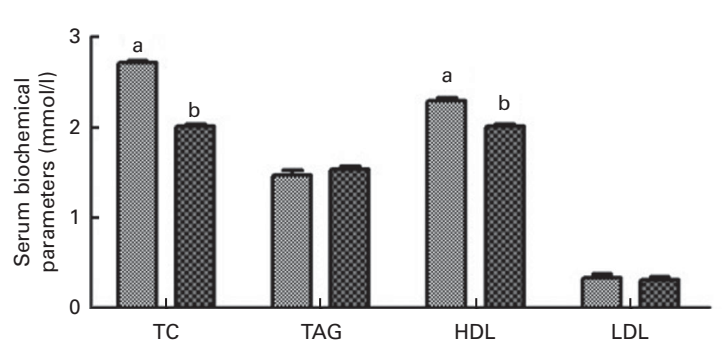

(D)

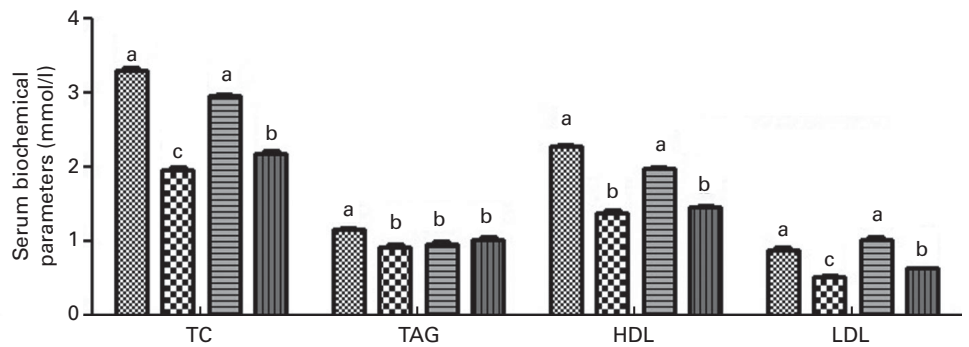

Fig. 3. Effects of the black bean seed coat extract on (A) body-weight gain, (B) food intake and (C, D) serum biochemical parameters in C57BL/6 mice. A total of forty-eight mice were randomised into six groups that received the following experimental diets for 5 weeks: CN, control diet $(n 7,(\mathrm{~A})-\bullet-$ and $(\mathrm{C})$ a); $\mathrm{CN}+\mathrm{FSE}(\mathrm{L})$

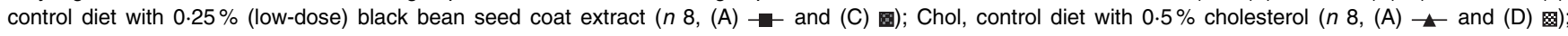
Chol+Sim, control diet with $0.5 \%$ cholesterol and $0.03 \%$ simvastatin (statin) $(n 8,(\mathrm{~A}) \rightarrow$ and $(\mathrm{D}) \mathrm{m})$ ); Chol $+\mathrm{FSE}(\mathrm{H})$, control diet with $0.5 \%$ cholesterol and $0.5 \%$ (high-dose) black bean seed coat extract ( $n$ 9, (A) $\multimap$ and (D) 冈x); Chol+FSE (L), control diet with $0.5 \%$ cholesterol and $0.25 \%$ (low-dose) black bean seed coat extract ( $n$ 8, (A) - - - and (D) 目). Body weight (A) and food intake (B) were measured every 3 to $5 \mathrm{~d}$. (C, D) At the end of the study, plasma was obtained from C57BL/6 mice that were fasted for $12 \mathrm{~h}$ to determine the serum biochemical parameters. Values are means, with their standard errors represented by vertical bars. ${ }^{a, b, c}$ Mean values with unlike letters were significantly different $(P<0.05)$. TC, total cholesterol.

analysis if the variables did not exhibit a normal distribution. Differences were considered to be significant at $P<0 \cdot 05$

\section{Results}

\section{Characterisation and composition of the black bean seed coat extract}

Quercetin 3-O-glucoside was the primary flavonoid identified in the extract of black bean seed coats (Fig. 1(A)), and the most abundant saponin was soyasaponin Af (Fig. 1(B)). In addition, other flavonoids and saponins were identified and quantified (Fig. 1(C)).

\section{Expression of lipogenic proteins and ATP-binding cassette, subfamily G, member 5}

The extract rich in flavonoids and saponins reduced the expression of both SREBP1C and FAS in primary rat hepatocytes. The synthetic ligand of LXR, T0901317, increased the expression of lipogenic proteins compared with the levels in the control group, as expected. Interestingly, the addition of the FSE partially repressed the stimulatory effect of T0901317 on the expression of the lipogenic proteins SREBP1C and $F A S$. In contrast, the expression of $A B C G 5$ was not repressed by the FSE, and this extract did not reduce the stimulatory effect of T0901317 on the expression of ABCG5. The potential effects of the FSE on genes involved in the $\beta$-oxidation of fatty acids, especially the rate-limiting enzyme CPT1, were also analysed in primary rat hepatocytes. The FSE had no effect on the expression of CPT1; however, it inhibited the suppressive effect of T0901317 on genes in primary hepatocyte cultures (Fig. 2(A))

The analysis of the FSE fractions revealed that both families of compounds, flavonoids and saponins, had effects similar to those observed with the FSE. The flavonoid-rich fraction had a stronger effect on the down-regulation of the expression of lipogenic proteins (Fig. 2(B)), whereas the saponin-rich fraction had a greater effect on the up-regulation of the expression of the transporter ABCG5 similar to the synthetic ligand of LXR, T0901317 (Fig. 2(C)).

\section{Plasma lipid profile in mice}

The addition of the FSE to the diets did not significantly change the body-weight gain among the groups during the 5-week study (Fig. 3(A)). We measured the average daily food intake of mice in all experimental groups, and no significant difference was found during the 5-week study (Fig. 3(B)). Interestingly, the FSE significantly reduced the levels of total cholesterol and HDL-cholesterol in the serum of mice fed the control diet These effects of the FSE were significantly enhanced in mice fed a high-cholesterol diet by decreasing the levels of 

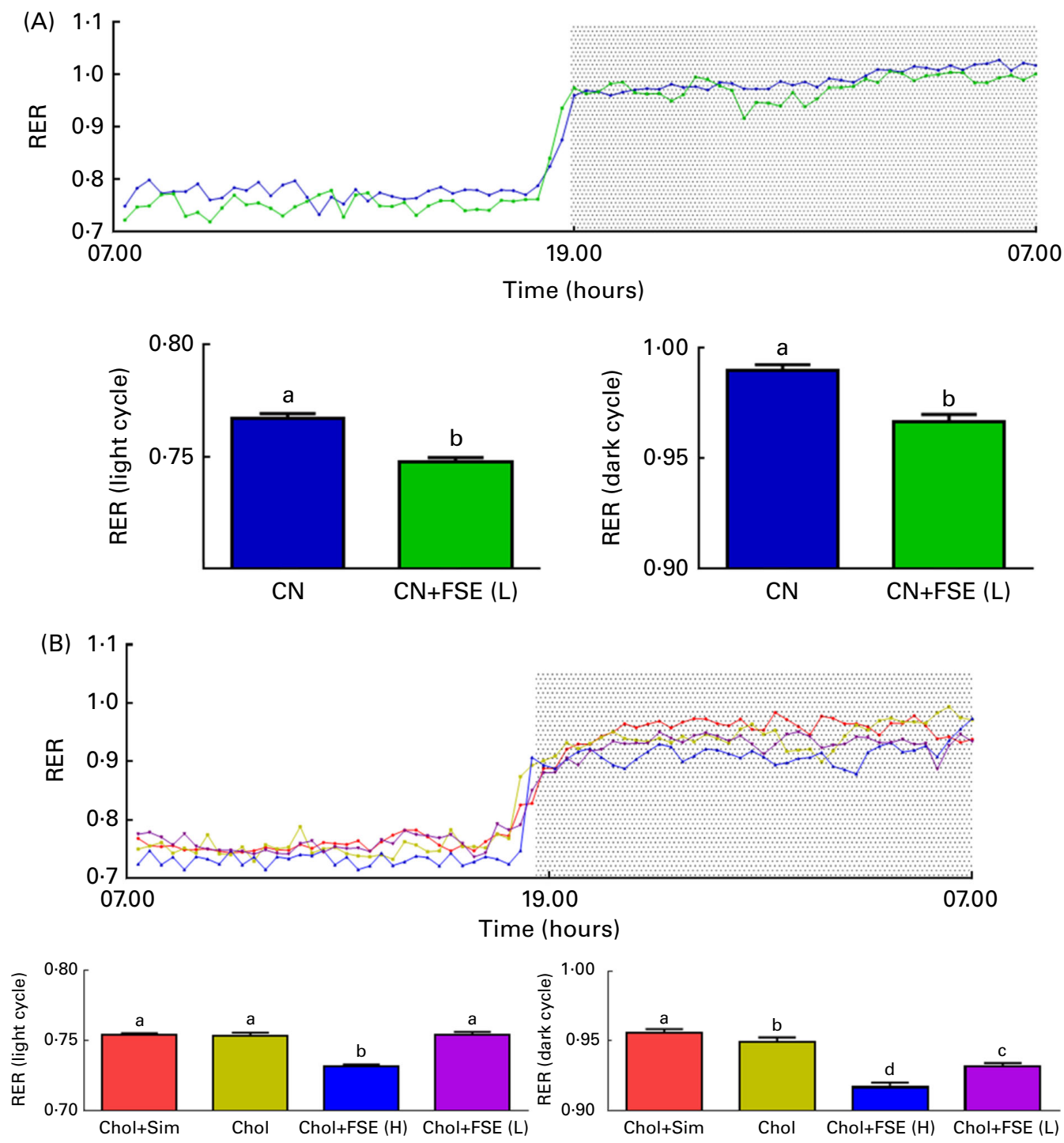

Fig. 4. Effects of the experimental diets on the average RER of C57BL/6 mice. C57BL/6 mice ( $n 3$ per group) were placed in metabolism cages and analysed for 3 d. (A) Average RER of mice fed the control diet (CN; $-\rightarrow)$ and the control diet with the black bean seed coat extract at a low dose (CN+FSE (L); $-\circ)$. RER (light cycle): $\mathrm{CN}-0.76$ (SE 0.002), lipids $=80.80 \%$, carbohydrates $=19.20 \%$; CN $+\mathrm{FSE}(\mathrm{L})-0.74$ (SE 0.001 ), lipids $=88 \%$, carbohydrates $=12 \%$. RER (dark cycle): $C N-0.98$ (SE 0.002), L = 6.37\%, carbohydrates $=93.7 \%$; CN FSE (L) - 0.96 (SE 0.003 ), lipids $=12.8 \%$, carbohydrates $=87.2 \%$. (B) Average RER of mice fed the control diet with cholesterol $(0.5 \%$, Chol; --$)$, the control diet with cholesterol $(0.5 \%)$ and the extract $(0.5 \%$, Chol +FSE $(\mathrm{H}) ;-\bullet)$, the control diet with cholesterol $(0.5 \%)$ and the extract $\left(0.25 \%\right.$, Chol+FSE (L); - - - ) and the control diet with cholesterol $(0.5 \%)$ and simvastatin $(0.03 \% \text {, Chol+Sim; } \rightarrow-)^{\circ}$. RER (light cycle): $\mathrm{Chol}+\mathrm{Sim}-0.75$ (SE 0.001), lipids $=84.4 \%$, carbohydrates $=15.6 \%$; Chol -0.75 (SE 0.002), lipids $=84.4 \%$, carbohydrates $=15.6 \% ;$ Chol + FSE (H) -0.73 (SE 0.001), lipids $=91.6 \%$, carbohydrates $=8.4 \%$; Chol+FSE (L) -0.75 (SE 0.002), lipids $=84.4 \%$, carbohydrates $=15.6 \%$. RER (dark cycle): Chol+Sim - 0.96 (SE 0.002), lipids $=12.8 \%$, carbohydrates $=87.2 \%$; Chol -0.95 (SE 0.003), lipids $=16.0 \%$, carbohydrates $=84.0 \%$; Chol+FSE (H) -0.92 (SE 0.003), lipids $=25.9 \%$, carbohydrates $=74.1 \%$; Chol $+\mathrm{FSE}(\mathrm{L})-0.93$ (SE 0.002), lipids $=22.6 \%$, carbohydrates $=77.4 \%$. The RER was calculated from $\mathrm{O}_{2}$ consumption and $\mathrm{CO}_{2}$ production at week 4 . The black bean seed coat extract decreased energy expenditure and induced lipid oxidation. Values are means, with their standard errors represented by vertical bars. ${ }^{\mathrm{a}, \mathrm{b}, \mathrm{c}, \mathrm{d}}$ Mean values with unlike letters were significantly different $(P<0 \cdot 05)$. A colour version of this figure can be found online at http://www.journals.cambridge.org/bjn

LDL-cholesterol and TAG in addition to the levels of total cholesterol and HDL-cholesterol (Fig. 3(C) and (D)). No significant differences were observed in the levels of serum insulin and glucose among the groups (data not shown).

\section{Effects of the black bean seed coat extract on the RER in mice}

The present results showed that the RER was significantly lower in the group fed with the FSE than in the control group, with a dose-dependent effect being observed. Although the RER differed between night and day, the trend remained the same. The effect of the FSE on the RER was more evident in mice fed the cholesterol-containing diets (Fig. 4).

\section{Effects of the black bean seed coat extract on lipogenesis in the liver of C57BL/6 mice}

The in vitro assays revealed that the FSE significantly decreased the expression of lipogenic proteins in the liver of 


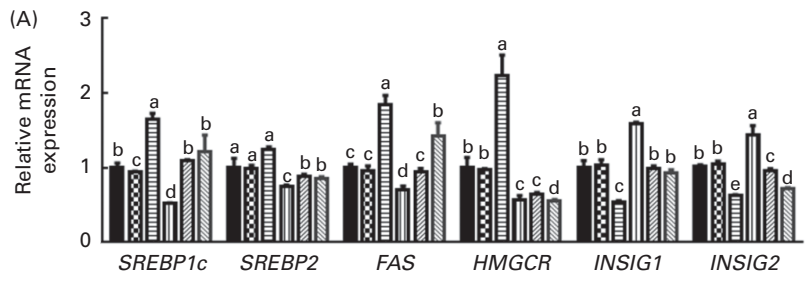

(B)
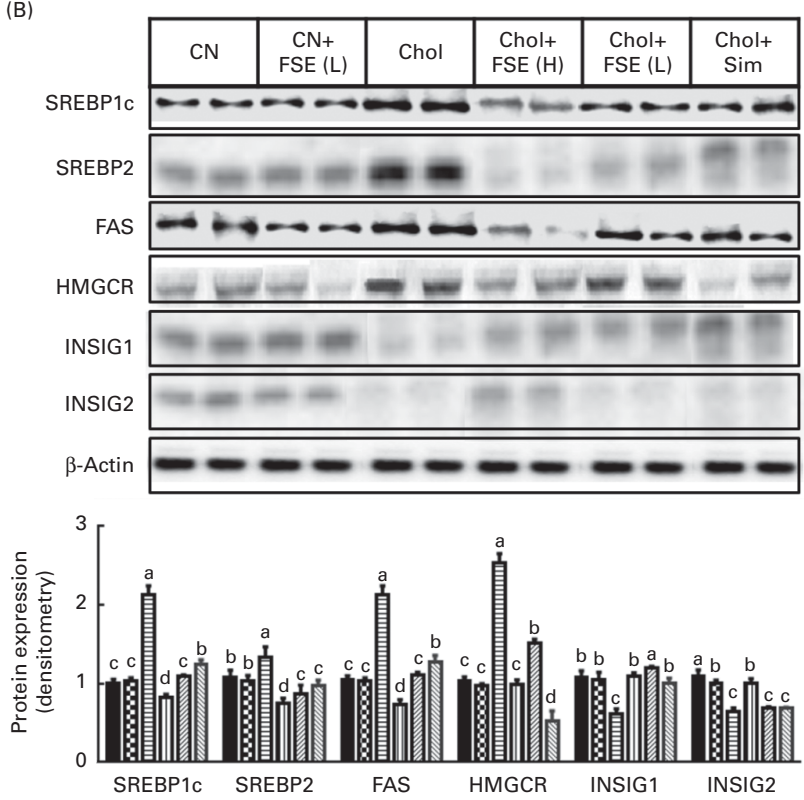

Fig. 5. Effects of the experimental diets on liver lipogenesis in C57BL/6 mice. (A) Relative mRNA expression levels of the lipogenic proteins sterol regulatory element-binding protein 1c (SREBP1C), SREBP2, fatty acid synthase $(F A S)$ and 3-hydroxy-3-methylglutaryl-CoA reductase (HMGCR) and of insulin-induced gene 1 (INSIG1) and INSIG2, key proteins involved in the degradation of SREBP proteins. (B) Protein expression levels of the same proteins determined by Western blotting. The experimental diets were as follows: $\mathrm{CN}$, control diet $(\square)$; $C N+F S E(L)$, control diet with the flavonoid- and saponinrich extract $(0.25 \%)$ (圆); Chol, control diet with cholesterol $(0.5 \%)$ (目); Chol+FSE $(\mathrm{H})$, control diet with cholesterol $(0.5 \%)$ and the extract $(0.5 \%)$ (四); Chol+FSE (L), control diet with cholesterol $(0.5 \%)$ and the extract $(0.25 \%)(\mathbb{Z})$; Chol+Sim, control diet with cholesterol $(0.5 \%)$ and simvastatin $(0.03 \%)(\mathbb{\$})$. The black bean seed coat extract significantly decreased the expression levels of lipogenic proteins in C57BL/6 mice. Values are means, with their standard errors represented by vertical bars. ${ }^{a, b, c, d, e}$ Mean values with unlike letters were significantly different $(P<0.05)$.

C57BL/ 6 mice. This decrease in the expression of lipogenic proteins was observed at both the mRNA (Fig. 5(A)) and protein (Fig. 5(B)) levels. Moreover, a dose-dependent effect was observed among the experimental groups fed with the FSE. Interestingly, we observed that the FSE induced the overexpression of INSIG1/INSIG2 (Fig. 5).

\section{Histological analysis}

Histological analysis of liver sections stained with haematoxylin and eosin (Fig. 6(A)) or Oil Red O (Fig. 6(B)) showed that mice fed the cholesterol diets had significantly greater hepatic fat accumulation than the control mice, and these results were confirmed by the quantification of hepatic lipid levels (Fig. 6(C)). Mice fed a diet containing cholesterol and
FSE at a low dose had a significant decrease in hepatic lipid depots; however, this reduction was only modest when compared with that in the group of mice fed a cholesterolcontaining diet with simvastatin. However, the addition of the FSE at a high dose to the cholesterol-containing diet had effects on the reduction of hepatic lipid levels similar to those observed in mice fed a cholesterol-containing diet with simvastatin. There was no difference in the hepatic lipid levels between the control groups fed the diets with and without the FSE (Fig. 6(C)).

\section{Effects of the black bean seed coat extract on bile acid synthesis}

Bile acid formation depends on the synthesis of bile acids as well as on the hepatic transport of cholesterol to the bile. These processes are mainly regulated by the enzyme cholesterol $7 \alpha$-hydroxylase (CYP7A1) and by the reverse cholesterol transporters, respectively. The present results showed that the expression of ABCG5/ABCG8 in the liver (Fig. 7(A)) and ileum (Fig. 7(B)) was significantly increased by the addition of the FSE to the diet. However, the cholesterol-containing diet with simvastatin down-regulated the expression of ABCG5/ ABCG8 in the ileum, promoting the absorption of cholesterol (Fig. 7(B)). Intriguingly, the FSE did not further stimulate LXR- $\alpha$ or PPAR- $\alpha$ expression in the ileum, suggesting that the FSE could modify LXR activity without an increase in the levels of LXR (data not shown). Additionally, the FSE stimulated bile acid synthesis via the up-regulation of CYP7A1 (Fig. 7(C)). As a result, we observed that the inclusion of the FSE in the diet increased the amount of bile acid in the stools of mice (Fig. 7(D)).

\section{Effects of black bean seed coat extract on liver $X$ receptor activity}

To determine how the FSE increased the activity of LXR, we first found that feeding the FSE resulted in a significant increase in the relative expression level of LXR as well as the protein level of LXR- $\alpha$ (Fig. 8(A) and (B), respectively) without any significant changes in the level of LXR- $\beta$ or farnesoid $\mathrm{X}$ receptor. We then found that LXR activity could be modulated by its phosphorylation. Particularly, phosphorylation of LXR- $\alpha$ by the enzyme AMPK reduced its capacity to stimulate the lipogenic genes. The present results suggest that the FSE could activate this mechanism, since the intake of the FSE increased the phosphorylation of AMPK which is the active form of this enzyme (Fig. 8(C)).

\section{Effects of the black bean seed coat extract on the expression of carnitine palmitoyltransferase I and PPAR- $\alpha$}

Surprisingly, cholesterol intake by $\mathrm{C} 57 \mathrm{BL} / 6$ mice decreased the expression levels of hepatic PPAR- $\alpha$ and CPT1. In contrast, mice fed the high-cholesterol diet with the FSE did not exhibit decreases in the expression levels of these proteins (Fig. 9). These results are in agreement with the in vitro data as 
(A)

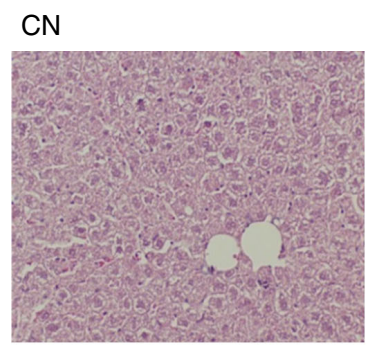

\section{Chol}

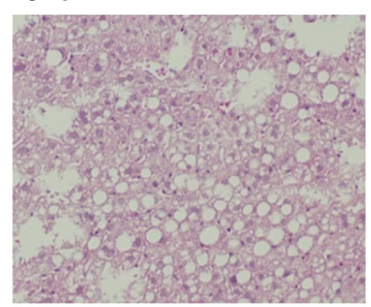

Chol+FSE $(\mathrm{H})$

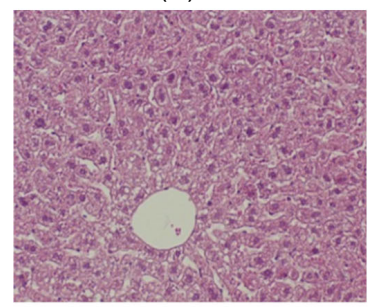

$\mathrm{CN}+\mathrm{FSE}(\mathrm{L})$

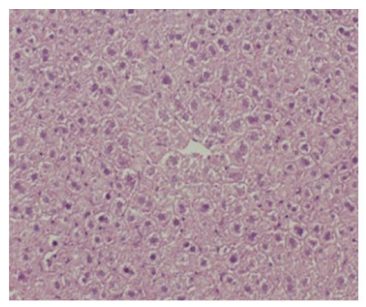

Chol+FSE (L)

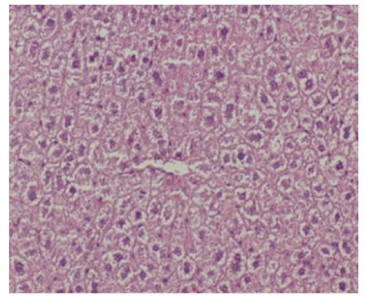

Chol+Sim $(H)$

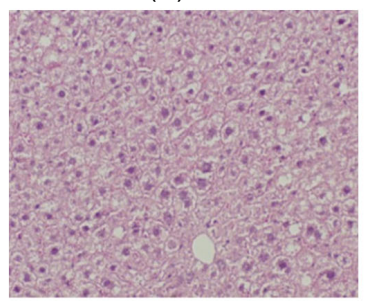

(B)

$\mathrm{CN}$

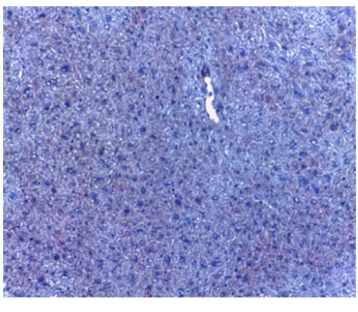

Chol

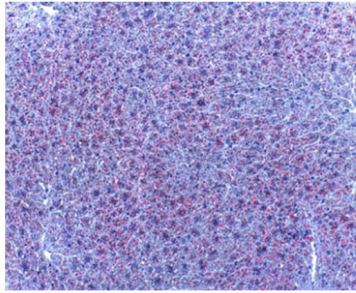

Chol+FSE (H)

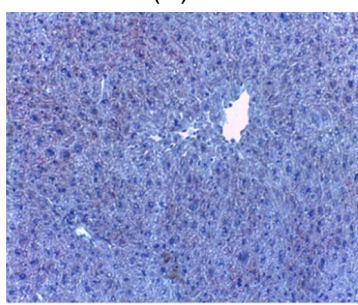

$\mathrm{CN}+\mathrm{FSE}(\mathrm{L})$

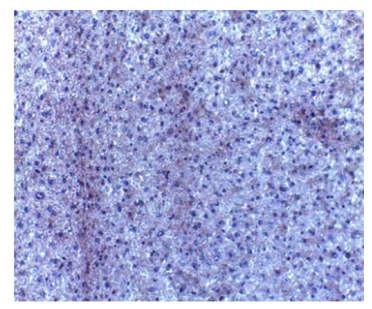

Chol+FSE (L)

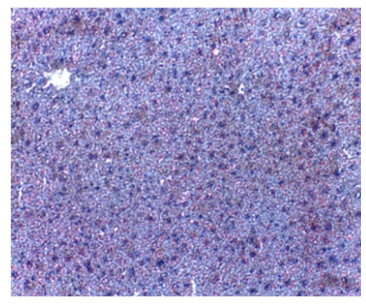

Chol+Sim $(H)$

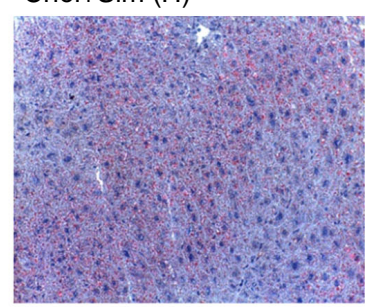

(C)

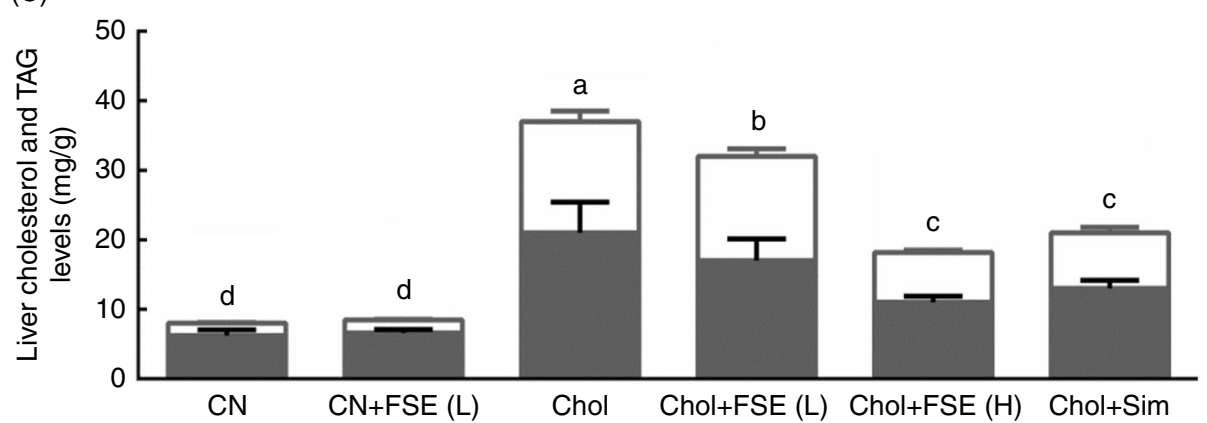

Fig. 6. Effects of the experimental diets on lipid accumulation in the liver of C57BL/6 mice. Hepatic tissue stained with (A) haematoxylin and eosin and (B) Oil Red $\mathrm{O}$, showing differences in lipid accumulation between the experimental groups. (C) Lipid accumulation in the liver was confirmed by the measurement of the cholesterol ( $\square$ ) and TAG $(\square)$ levels. The experimental diets were as follows: CN, control diet; CN+FSE (L), control diet with the flavonoid- and saponin-rich extract ( $0.25 \%)$; Chol, control diet with cholesterol $(0.5 \%)$; Chol+FSE(L), control diet with cholesterol $(0.5 \%)$ and the extract $(0.25 \%)$; Chol+FSE (H), control diet with cholesterol $(0.5 \%)$ and the extract $(0.5 \%)$; Chol+Sim, control diet with cholesterol $(0.5 \%)$ and simvastatin $(0.03 \%)$. Values are means, with their standard errors represented by vertical bars. $\mathrm{a}, \mathrm{b}, \mathrm{c}, \mathrm{d}$ Mean values with unlike letters were significantly different $(P<0.05)$. A colour version of this figure can be found online at http:// www.journals.cambridge.org/bjn

well as the RER, suggesting that the FSE could stimulate the $\beta$-oxidation of fatty acids.

\section{Discussion}

In the present study, we examined the effect of flavonoids and saponins extracted from black bean seed coats on the expression of key proteins involved in the regulation of lipid and cholesterol metabolism. We first examined the effect of the FSE on proteins regulated by the transcription factor LXR in primary rat hepatocytes. The results showed that the extract reduced the expression of lipogenic proteins, but induced the expression of reverse cholesterol transport such as ABCG5. Furthermore, the addition of the FSE to the diet repressed the stimulatory effect of synthetic LXR ligands on lipogenic proteins, but, again, this extract did not reduce the stimulatory effect of T0901317 on the expression of ABCG5. Interestingly, despite the FSE having no effect on the expression of CPT1, it inhibited the suppressive effect of T0901317 on this ratelimiting enzyme of fatty acid $\beta$-oxidation. These results 
(A)

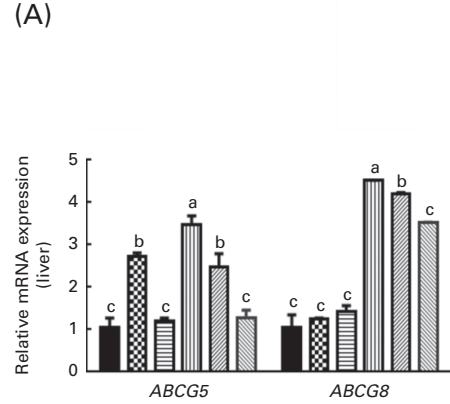

(B)

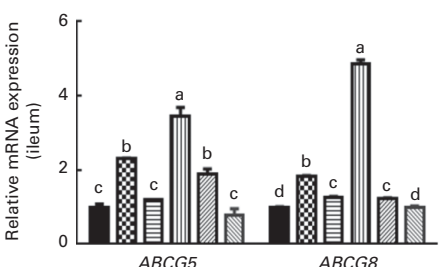

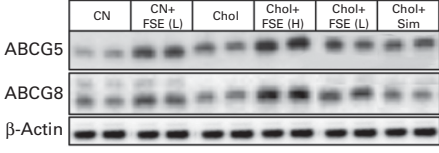
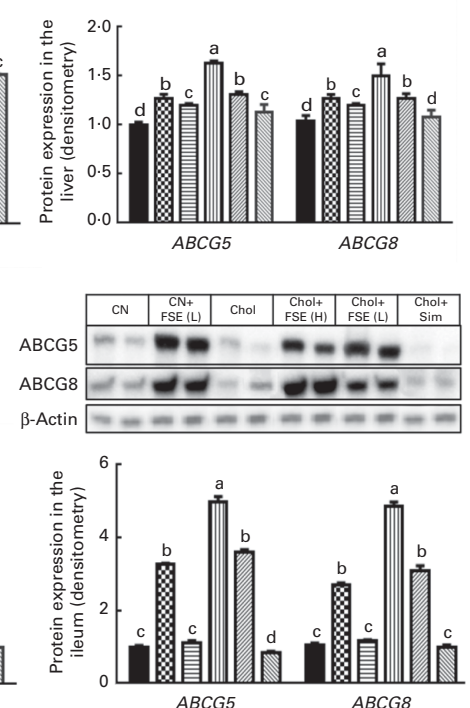

(C)
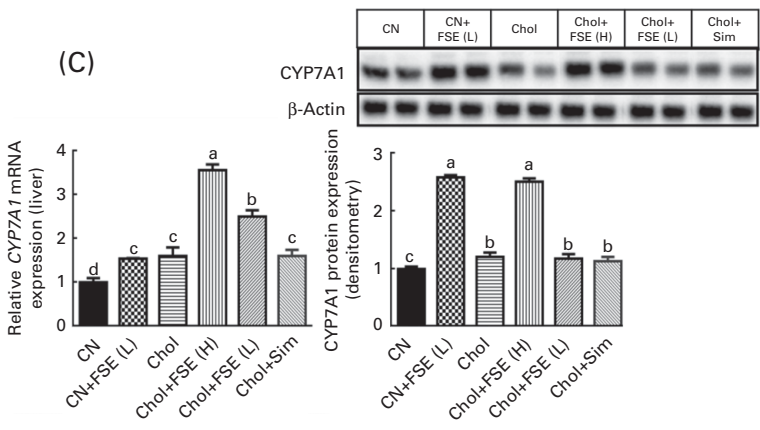

(D)

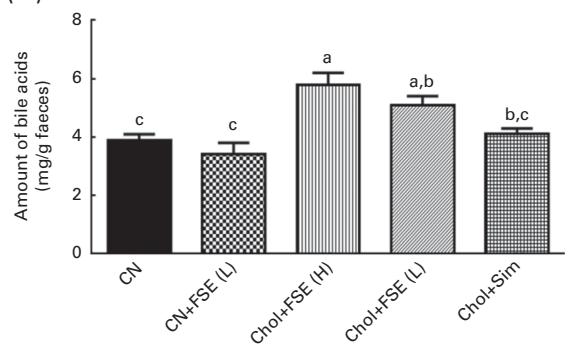

Fig. 7. Effects of the black bean seed coat extract on liver and intestinal cholesterol, biliary cholesterol secretion, and the liver expression of the rate-limiting enzyme in the synthesis of bile acids. (A) In the liver, the black bean seed coat extract significantly increased the relative protein expression levels of ATP-binding cassette, subfamily G5 (ABCG5)/ABCG8. These proteins mediated the excretion of free cholesterol into the bile. (B) In the ileum, ABCG5/ABCG8 suppressed the absorption of sterols. This suppressive effect was increased in the experimental groups fed the extract. (C) The level of cholesterol 7 $\alpha$-hydroxylase (CYP7A1), which catalysed the rate-limiting step in the synthesis of bile acids, was up-regulated in the liver by the extract. (D) The amount of bile acid was increased in the stools of mice fed the extract. The experimental diets were as follows: CN, control diet ( $\square$ ); CN+FSE (L), control diet with the flavonoid- and saponin-rich extract

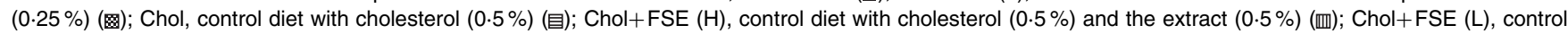
diet with cholesterol $(0.5 \%)$ and the extract $(0.25 \%)(\mathbb{Z})$; Chol+Sim, control diet with cholesterol $(0.5 \%)$ and simvastatin $(0.03 \%)(\mathbb{N})$. Values are means, with their standard errors represented by vertical bars. ${ }^{\mathrm{a}, \mathrm{b}, \mathrm{c}, \mathrm{d}}$ Mean values with unlike letters were significantly different $(P<0.05)$.

suggested that flavonoids and saponins extracted from black bean seed coats were capable of regulating the activity of LXR. Moreover, studies with flavonoid- and saponin-rich fractions have suggested that there is a synergistic effect exerted by flavonoids and saponins contained in the extract to control lipogenesis as well as reverse cholesterol transport.

To understand the potential physiological relevance of in vitro studies on cholesterol and fatty acid metabolism, we then studied the effects of the FSE in C57BL/6 mice fed diets with or without cholesterol. Metabolic changes were not associated with differences in food intake among the groups, and as a result, at the end of the study, there was no significant difference in weight gain among the groups. The present data showed that the plasma lipid profile was indeed improved by feeding the extract in mice. Additionally, analysing the RER, we observed that the FSE was able to modulate the type of energy substrate for energy generation used by mice. The present data indicated that the proportion of lipids used as a substrate for energy generation was greater in mice fed the FSE than in mice fed the control diets or diets with simvastatin. The control diet containing cholesterol increased the expression of SREBP1C possibly by activating LXR and hence the lipogenesis programme ${ }^{(31)}$.

The beneficial effect of the FSE on decreasing the levels of serum cholesterol in C57BL/6 mice was associated with a reduction in hepatic lipogenesis and cholesterol biosynthesis through the down-regulation of SREBP1C, FAS and HMGCR and the up-regulation of INSIG1/INSIG2. It has been demonstrated that overexpression of INSIG1 traps the SCAP (SREBP cleavage-activating protein)/SREBP complex in the endoplasmic reticulum, promoting SREBP degradation and reducing the ability of SREBP to activate the transcription of genes that encode enzymes involved in cholesterol and fatty acid biosynthesis $^{(32)}$. A similar down-regulatory effect of lipogenic proteins by the consumption of wild blueberry-enriched $\operatorname{diet}^{(33)}$ and coumarin has been reported, the latter was related to an attenuation of hepatic steatosis ${ }^{(34)}$.

We then studied cholesterol metabolism, which showed an increment in the mRNA abundance of SREBP2 and HMGCR in mice fed the control diet with cholesterol. In agreement with previous studies, we showed that simvastatin decreased the levels of HMGCR more than those of the other lipogenic proteins. Interestingly, the addition of cholesterol to the diet did not significantly change the abundance of SREBP2 mRNA; however, the level of the mature form of SREBP2 was significantly increased, indicating an increase in the processing of the precursor form of SREBP2 in the Golgi ${ }^{355}$. The increase in the concentration of this transcription factor was markedly reduced when mice were fed the FSE, reducing the cholesterol biosynthetic programme.

To reduce the concentration of hepatic cholesterol, the FSE increased the expression of genes involved in bile acid synthesis, 


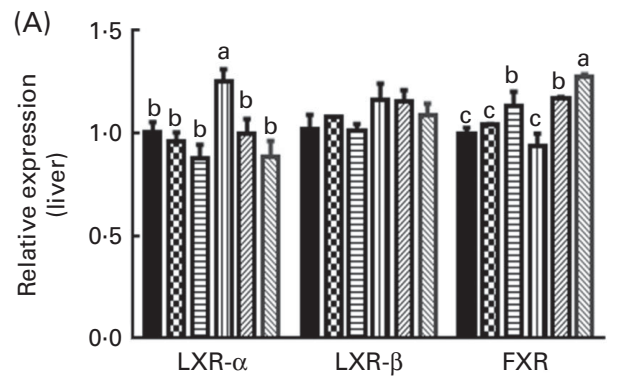

(B)
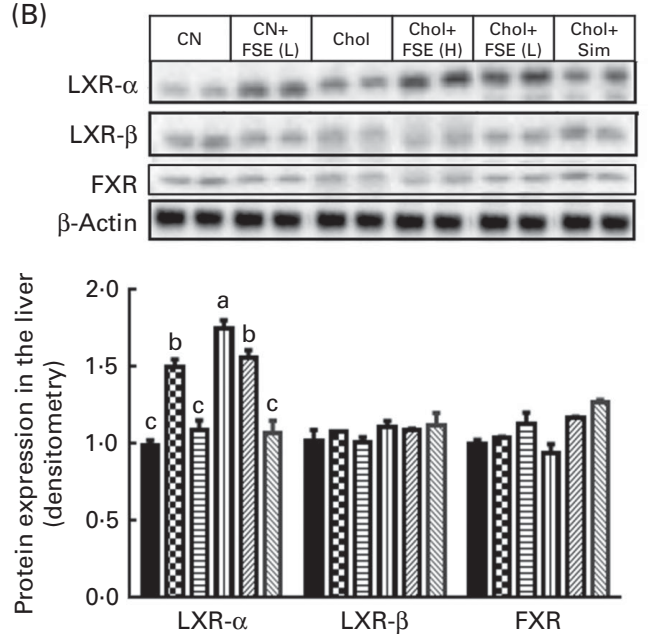

(C)
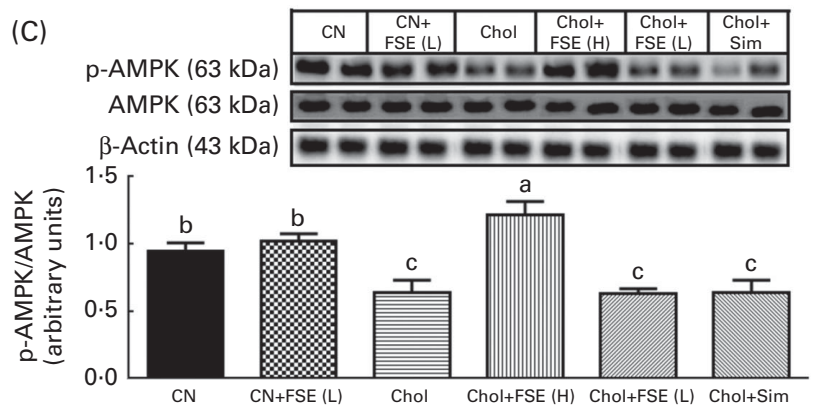

Fig. 8. Effects of the black bean seed coat extract on liver $X$ receptor (LXR), farnesoid $X$ receptor (FXR) and the phosphorylation of AMP-activated protein kinase (p-AMPK). The extract significantly increased (A) the relative expression levels of hepatic FXR and LXR- $\alpha$, (B) the protein abundance of LXR- $\alpha$ and (C) the phosphorylation of AMPK in the liver, which might activate LXR. The experimental diets were as follows: CN, control diet ( $\square$ ); CN+FSE

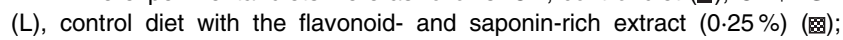
Chol, control diet with cholesterol $(0.5 \%)($ 目); Chol+FSE $(\mathrm{H})$, control diet with cholesterol $(0.5 \%)$ and the extract $(0.5 \%)(\mathbb{m})$; Chol+FSE (L), control diet with cholesterol $(0.5 \%)$ and the extract $(0.25 \%)($ Z $)$; Chol+Sim, control diet with cholesterol $(0.5 \%)$ and simvastatin $(0.03 \%)(\mathbb{\$})$. Values are means, with their standard errors represented by vertical bars. ${ }^{a, b, c}$ Mean values with unlike letters were significantly different $(P<0.05)$.

particularly $C Y P 7 A 1$, as well as in reverse cholesterol transport, such as $A B C G 5 / A B C G 8$; in addition, the FSE stimulated the expression of $A B C G 5 / A B C G 8$ in the intestine. In the liver, $A B C G 5 / A B C G 8$ drives the elimination of hepatic cholesterol into the bile, whereas in the intestine, it suppresses the absorption of biliary and dietary sterols ${ }^{(36,37)}$. The effective suppression of the accumulation of dietary cholesterol appears to require the overexpression of both intestinal and hepatic $A B C G 5 /$ $A B C G 8^{(37)}$. This effect has been shown to be related to protection against atherosclerosis $^{(38)}$. Additionally, CYP7A1 is the rate-limiting step in the synthesis of bile acid from cholesterol ${ }^{(39)}$. Hence, the results indicated that the FSE promoted the secretion of biliary cholesterol and reduced the absorption of dietary cholesterol. This result showing the stimulation of the expression of these genes by the FSE was associated with an increase in faecal bile acids. Interestingly, we observed a down-regulation of $A B C G 5$ in the intestine due to simvastatin, an effect that has been reported previously ${ }^{(40)}$, suggesting that statins potentially can increase the absorption of intestinal cholesterol. Therefore, the FSE was represented as a prospectively more effective treatment to decrease cholesterol absorption by the up-regulation of $A B C G 5 / A B C G 8$.

To elucidate the possible mechanism by which the FSE regulated the expression of genes involved in lipogenesis and reverse cholesterol transport (Fig. 10), it is important to point out that these genes are primarily controlled by the transcription factor LXR. The activity of these transcription factors is regulated by the binding of their natural or synthetic ligands, and also by its phosphorylation state. Recent evidence shows that isoflavones, particularly genistein, can modulate LXR activity by controlling the phosphorylation state of this nuclear receptor $^{(29)}$. Phosphorylation of LXR- $\alpha$ and LXR- $\beta$ can be triggered by the enzyme AMPK, resulting in the modulation of their biological activity in an opposite manner. In the present study, we demonstrated that the FSE stimulated the phosphorylation state of AMPK. Therefore, it is possible to suggest that the FSE up-regulates $A B C G 5 / A B C G 8$ and $C Y P 7 A 1$, suggesting tentatively the promotion of the excretion and
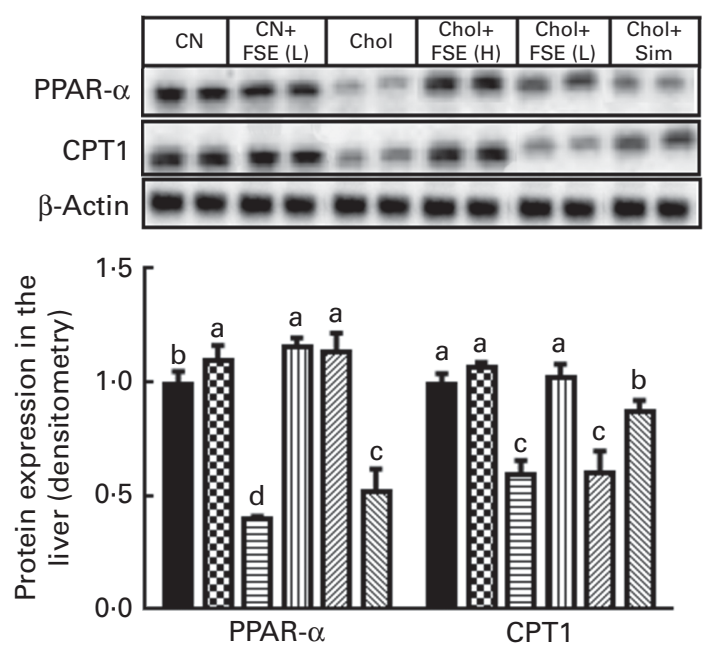

Fig. 9. Effects of the experimental diets on $\beta$-oxidation in the liver of C57BL/6 mice. The black bean seed coat extract at a high concentration significantly suppressed the effect of cholesterol on the protein expression levels of PPAR- $\alpha$ and carnitine palmitoyltransferase 1 (CPT1). The experimental diets were as follows: CN, control diet ( $\square$ ); CN+FSE (L), control diet with the flavonoid- and saponin-rich extract $(0.25 \%)$ (圈); Chol, control diet with cholesterol $(0.5 \%)($ 目); Chol+FSE $(\mathrm{H})$, control diet with cholesterol $(0.5 \%)$ and the extract $(0.5 \%)(\mathbb{m})$; Chol+FSE (L), control diet with cholesterol $(0.5 \%)$ and the extract $(0.25 \%)(\mathbb{Z})$; Chol+Sim, control diet with cholesterol $(0.5 \%)$ and simvastatin $(0.03 \%)(\mathbb{N})$. Values are means, with their standard errors represented by vertical bars. ${ }^{a, b, c, d}$ Mean values with unlike letters were significantly different $(P<0.05)$. 

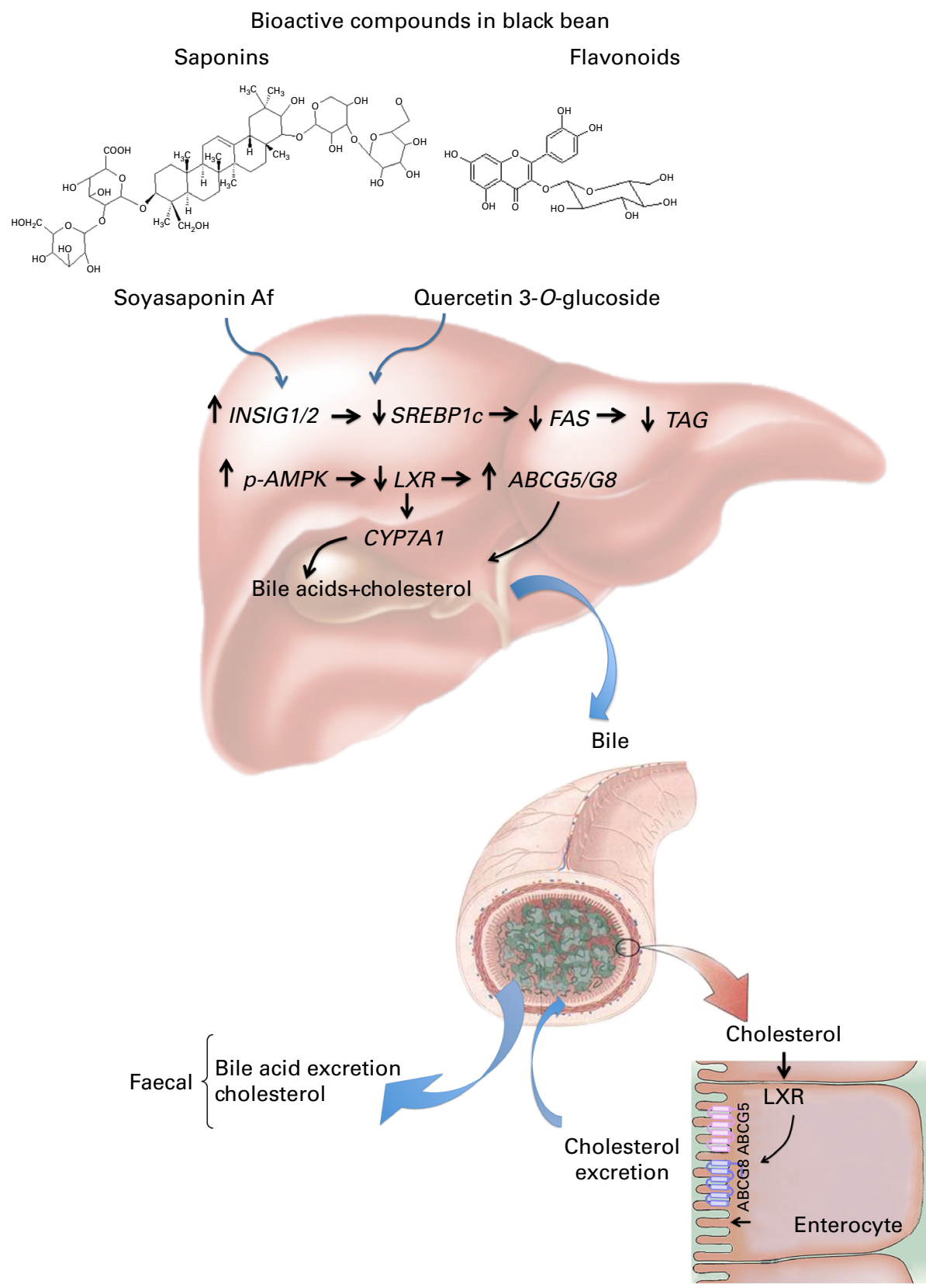

Fig. 10. Proposed model for the mechanism by which flavonoids and saponins extracted from black bean (Phaseolus vulgaris $\mathrm{L}$.) seed coats modulate lipid metabolism and biliary cholesterol secretion. INSIG1/2, insulin-induced gene 1/2; SREBP1c, sterol regulatory element-binding protein 1; FAS, fatty acid synthase; p-AMPK, phosphorylation of AMP-activated protein kinase; LXR, liver X receptor; ABCG5/G8, ATP-binding cassette, subfamily G5/G8; CYP7A1, cholesterol $7 \alpha$-hydroxylase. A colour version of this figure can be found online at http://www.journals.cambridge.org/bjn

catabolism of cholesterol $^{(41)}$, but suppresses the expression of lipogenic proteins via LXR. In contrast, it has been suggested that LXR activation inhibits fatty acid oxidation by interfering with the binding of PPAR- $\alpha$ to its target sites ${ }^{(42)}$. We observed that cholesterol decreased the expression of PPAR- $\alpha$ and CPT1. Surprisingly, the FSE prevented the decrease in the expression of these genes in the liver, possibly stimulating fatty acid oxidation despite the presence of cholesterol in the diet.

In summary, the present results suggest that flavonoids and saponins extracted from black bean seed coats could potentially prevent hepatic lipid accumulation by attenuating lipogenesis and stimulating fatty acid oxidation and biliary cholesterol excretion through the differential regulation of LXR probably mediated by the phosphorylation of AMPK.

\section{Acknowledgements}

The present study was supported by the Nutrigenomic Research Chair Funds from Tecnologico de MonterreyCampus Monterrey and Consejo Nacional de Ciencia y Tecnología. 
R. A. C.-S. was responsible for the experimental design, analysed the data and wrote the manuscript; J. A. G.-U., O. G. and I. T.-V. analysed data; S. O. S.-S., and N. T. were responsible for the experimental design and data analysis. B. P.-G. analysed the data. A. R. T. contributed to the experimental design and discussion and wrote the manuscript.

\section{References}

1. Garcia-Rios A, Perez-Martinez P, Delgado-Lista J, et al. (2012) Nutrigenetics of the lipoprotein metabolism. Mol Nutr Food Res 56, 171-183.

2. Mason JC (2003) Statins and their role in vascular protection. Clin Sci 105, 251-266.

3. National Cholesterol Education Program (NCEP) (2002) Detection, Evaluation, and Treatment of High Blood Cholesterol in Adults (ATP III): Final Report. Bethesda, MD: National Institutes of Health.

4. Anderson J (2003) Diet first, then medication for hypercholesterolemia. JAMA 290, 2002-2004.

5. Nguyen TT (1999) The cholesterol-lowering action of plant stanol esters. J Nutr 129, 2109.

6. Chen ZY, Jiao R \& Ma KY (2008) Cholesterol-lowering nutraceuticals and functional foods. J Agric Food Chem 56, 8761-8773.

7. Tovar AR, Torre-Villalvazo I, Ochoa M, et al. (2005) Soy protein reduces hepatic lipotoxicity in hyperinsulinemic obese Zucker fa/fa rats. J Lipid Res 46, 1823-1832.

8. Kishi S, Tanabe K, Yachi S, et al. (2012) Impact of $3 / 6$ polyunsaturated fatty acids ratio on the prevalence of coronary artery disease assessed by 320-Row Ct coronary angiography. J Am Coll Cardiol 59, E1654.

9. Jia Y, Kim JY, Jun HJ, et al. (2012) The natural carotenoid astaxanthin, a PPAR- $\alpha$ agonist and PPAR- $\gamma$ antagonist, reduces hepatic lipid accumulation by rewiring the transcriptome in lipid-loaded hepatocytes. Mol Nutr Food Res 56, 878-888.

10. Bladé C, Baselga-Escudero L, Salvadó MJ, et al. (2013) miRNAs, polyphenols, and chronic disease. Mol Nutr Food Res 57, 58-70.

11. Micallef MA \& Garg ML (2008) The lipid-lowering effects of phytosterols and (n-3) polyunsaturated fatty acids are synergistic and complementary in hyperlipidemic men and women. J Nutr 138, 1086-1090.

12. Wang Y, Jia X, Ghanam K, et al. (2010) Berberine and plant stanols synergistically inhibit cholesterol absorption in hamsters. Atherosclerosis 209, 111-117.

13. Jain D, Ebine N, Jia X, et al. (2008) Corn fiber oil and sitostanol decrease cholesterol absorption independently of intestinal sterol transporters in hamsters. $J$ Nutr Biochem 19, 229-236.

14. Marzolo MP, Amigo L \& Nervi F (1993) Hepatic production of very low density lipoprotein, catabolism of low density lipoprotein, biliary lipid secretion, and bile salt synthesis in rats fed a bean (Phaseolus vulgaris) diet. J Lip Res 34, 807-814.

15. Rosa CO, Costa NM, Leal PF, et al. (1998) The cholesterollowering effect of black beans (Phaseolus vulgaris, L.) without hulls in hypercholesterolemic rats. Arch Latinoam Nutr 48, 299-305.

16. Guajardo-Flores D, García-Patiño M, Serna-Guerrero D, et al. (2012) Characterization and quantification of saponins and flavonoids in sprouts, seed coats and cotyledons of germinated black beans. Food Chem 134, 1312-1319.
17. Middleton E, Kandaswami C \& Theoharides TC (2000) The effects of plant flavonoids on mammalian cells: implications for inflammation, heart disease, and cancer. Pharmacol Rev 52, 673-751.

18. Berhow MA, Bin Kong S, Vermillion KE, et al. (2006) Complete quantification of group A and group B soyasaponins in soybeans. J Agric Food Chem 54, 2035-2044.

19. Potter SM (1995) Overview of proposed mechanisms for the hypocholesterolemic effect of soy. J Nutr 125, 606S-611S.

20. Sato R (2002) Sterol metabolism and SREBP activation. Arch Biochem Biophys 501, 177-181.

21. Horton J (2002) SREBPs: activators of the complete program of cholesterol and fatty acid synthesis in the liver. J Clin Invest 109, 1125-1131.

22. Pawar A, Botolin D, Mangelsdorf DJ, et al. (2003) The role of liver $\mathrm{X}$ receptor-alpha in the fatty acid regulation of hepatic gene expression. J Biol Chem 278, 40736-40743.

23. Calpe-Berdiel L, Rotllan N, Fiévet C, et al. (2008) Liver X receptor-mediated activation of reverse cholesterol transport from macrophages to feces in vivo requires ABCG5/G8. J Lipid Res 49, 1904-1911.

24. Repa JJ, Berge KE, Pomajzl C, et al. (2002) Regulation of ATP-binding cassette sterol transporters ABCG5 and ABCG8 by the liver X receptors $\alpha$ and $\beta$. J Biol Chem 277 , 18793-18800.

25. Graf G, Li W \& Gerard R (2002) Coexpression of ATP-binding cassette proteins ABCG5 and ABCG8 permits their transport to the apical surface. J Clin Invest 110, 659-669.

26. Berry MN \& Friend DS (1969) High-yield preparation of isolated rat liver parenchymal cells: a biochemical and fine structural study. J Cell Biol 43, 506-520.

27. Reeves PG, Nielsen FH \& Fahey GC (1993) AIN-93 purified diets for laboratory rodents: final report of the American Institute of Nutrition ad hoc writing committee on the reformulation of the AIN-76A rodent diet. J Nutr 123, 1939-1951.

28. Livak KJ \& Schmittgen TD (2001) Analysis of relative gene expression data using real-time quantitative PCR and the 2(-Delta Delta C(T)) method. Methods 25, 402-408.

29. González-Granillo M, Steffensen KR, Granados O, et al. (2012) Soy protein isoflavones differentially regulate liver X receptor isoforms to modulate lipid metabolism and cholesterol transport in the liver and intestine in mice. Diabetologia 22, 2469-2478.

30. Batta AK, Salen G, Rapole KR, et al. (1999) Highly simplified method for gas-liquid chromatographic quantitation of bile acids and sterols in human stool. J Lipid Res 40, 1148-1154.

31. Cha JY \& Repa JJ (2007) The liver X receptor (LXR) and hepatic lipogenesis. The carbohydrate-response elementbinding protein is a target gene of LXR. J Biol Chem 282, 743-751.

32. Engelking LJ, Kuriyama H, Hammer RE, et al. (2004) Overexpression of Insig-1 in the livers of transgenic mice inhibits SREBP processing and reduces insulin-stimulated lipogenesis. J Clin Invest 113, 1168-1175.

33. Vendrame S, Daugherty A, Kristo AS, et al. (2014) Wild blueberry (Vaccinium angustifolium)-enriched diet improves dyslipidaemia and modulates the expression of genes related to lipid metabolism in obese Zucker rats. Br J Nutr 111, 194-200.

34. Um MY, Moon MK, Ahn J, et al. (2013) Coumarin attenuates hepatic steatosis by down-regulating lipogenic gene expression in mice fed a high-fat diet. Br J Nutr 109, 1590-1597.

35. Brown MS \& Goldstein JL (1997) The SREBP pathway: regulation of cholesterol metabolism by proteolysis of a membrane-bound transcription factor. Cell 89, 331-340. 
36. Yu L \& Li-Hawkins J (2002) Overexpression of ABCG5 and ABCG8 promotes biliary cholesterol secretion and reduces fractional absorption of dietary cholesterol. J Clin Invest 110, 671-680.

37. Sabeva NS (2011) Regulation of ABCG5 and ABCG8 sterol transporters in biliary cholesterol elimination, reverse cholesterol transport and dyslipidemia. University of Kentucky Doctoral Dissertations.

38. Lo Sasso G, Murzilli S, Salvatore L, et al. (2010) Intestinal specific LXR activation stimulates reverse cholesterol transport and protects from atherosclerosis. Cell Metab 12, 187-193.
39. Cohen JC, Cali JJ, Jelinek DF, et al. (1992) Cloning of the human cholesterol $7 \alpha$-hydroxylase gene (CYP7A1) and localization to chromosome 8q11-q12. Genomics 14, 153-161.

40. Borthwick F, Mangat R, Warnakula S, et al. (2014) Simvastatin treatment upregulates intestinal lipid secretion pathways in a rodent model of the metabolic syndrome. Atherosclerosis 232, 141-148.

41. Schulman I (2010) Nuclear receptors as drug targets for metabolic disease. Adv Drug Deliv Rev 62, 1307-1315.

42. Handschin C \& Meyer UA (2005) Regulatory network of lipid-sensing nuclear receptors: roles for CAR, PXR, LXR, and FXR. Arch Biochem Biophys 433, 387-396. 